Mots. Les langages du politique

$80 \mid 2006$

La politique mise au net

\title{
Bibliographie thématique (2001-2005. Internet et les langages du politique
}

Marc Bonhomme et Michael Rinn

\section{OpenEdition}

Journals

Édition électronique

URL : https://journals.openedition.org/mots/17233

DOI : $10.4000 /$ mots. 17233

ISSN : 1960-6001

Éditeur

ENS Éditions

Édition imprimée

Date de publication : 1 mars 2006

Pagination : 87-89

ISBN : 2-84788-095-X

ISSN : 0243-6450

Référence électronique

Marc Bonhomme et Michael Rinn, « Bibliographie thématique (2001-2005. Internet et les langages du politique », Mots. Les langages du politique [En ligne], 80 | 2006, mis en ligne le 01 mars 2008, consulté le 23 avril 2022. URL : http://journals.openedition.org/mots/17233; DOl : https://doi.org/10.4000/ mots. 17233 


\section{Bibliographie thématique Internet et les langages du politique}

ABRAMSON J. B., ARTERTON F. C. et al., 1988, The Electronic Commonwealth. The Impact of New Media Technologies on Democratic Politics, New York, Basic Books, 331 p. AITCHISON J., 2002, The Language Web, Cambridge, Cambridge University Press, 139 p. ANIS J. éd., 1999, Internet: communication et langue française, Paris, Hermès, 191 p. BÉRA M. et MECHOULAN E., 1999, La machine Internet, Paris, Odile Jacob, 318 p.

BOARDMAN M., 2005, The Language of Websites, Londres, New York, Routledge, 117 p. BOULLIER D., 2000, « La nouvelle matérialité de l'espace public: les dispositifs de la netpolitique ", Hermès, n 26-27, p. 201-211.

BRETON P. et PROULX S., 1996, L'explosion de la communication, Paris, La Découverte, $323 \mathrm{p}$.

BYSTROM D. G. et KAID L. L., 1999, The Electronic Election: Perspective on the 1996 Campaign Communication, Mahwah, Lawrence Erlbaum, 415 p.

CALOT P. et LERMUSIAUX J.-C., 1998, "La communication politique sur Internet », http://www.chugu.com/recherches/com.politique.internet.html.

CORRADO A. et CHARLES M. F. éd., 1997, Elections in Cyberspace: Towards a New Era in American Politics, Washington, The Aspen Institute, $104 \mathrm{p}$.

CRYSTAL D., 2003, Language and the Internet, Cambridge, Cambridge University Press, $272 \mathrm{p}$.

CUSIN-BERCHE F. et MOURLHON-DALLIES F., 2000, « Le débat autour des OGM sur Internet: entre parole citoyenne et parole savante ", Les Carnets du Cediscor, n 6, p. 113-126.

DAVIS R. et OWEN D., 1998, New Media and American Politics, New York, Oxford University Press, $304 \mathrm{p}$.

DAVIS R., 1999: The Web of Politics: The Internet's Impact on the American Political System, New York, Oxford University Press, 225 p.

DÉJOND A., 2002, La cyberlangue française, Tournai, La Renaissance du Livre, 135 p.

ETHUIN N. et LEFEBVRE R., 2003, « Les balbutiements de la cyberdémocratie électorale. Contribution à une analyse des usages politiques d'Internet: le site de Martine Aubry lors des élections municipales de mars 2002 ", V. Serfaty éd., L'Internet en politique, Strasbourg, Presses universitaires de Strasbourg, p. 155-177.

FLICHY P., 2001, L'imaginaire d'Internet, Paris, La Découverte, 272 p.

GODELUCK D., 2002, Géopolitique d'Internet, Paris, La Découverte, 250 p.

GOUREVITCH J.-P., 1998, L'image en politique: de Luther à Internet et de l'affiche au clip, Paris, Hachette, $247 \mathrm{p}$.

GRANJON F., 2001, L'Internet militant. Mouvement social et usage des réseaux télématiques, Rennes, Apogée, 189 p. 
GREFFET F., 2001, « Les partis politiques français sur le Web », D. Andolfatto, F. Greffer et L. Olivier éd., Les partis politiques: quelles perspectives?, Paris, L'Harmattan, p. 161178.

GROSSMAN L. K., 1996, The Electronic Republic: Reshaping Democracy in the Information Age, New York, Penguin Books, 290 p.

GUÉGUEN N. et TOBIN L. éd., 1998, Communication, sociétés et Internet, Paris, L'Harmattan, $384 \mathrm{p}$.

GULATI GIRISH J., 2004, " Members of Congress and presentation of self on the World Wide Web », The Harvard International Journal of Press/Politics, $\mathrm{n}^{\circ}$ 9, p. 22-40.

HAGUE B. et LOADER B. éd., 1999, Digital Democracy: Discourse and Democracy in the Information Age, Londres, Routledge, $277 \mathrm{p}$.

HALLETT R. et KAPLAN-WEINGER N., 2004, "The construction of independence: a multimodal discourse analysis of Lithuanian websites », F. Baider, M. Burger et D. Goutsos éd., La communication touristique. Approches discursives de l'identité et de l'altérité, Paris, L'Harmattan, p. 215-234.

HILL K. A. et HUGHES J. E., 1998, Cyberpolitics: Citizen Activism in the Ages of the Internet, Lanham, Rowman et Littlefield, 207 p.

HOLMES D. éd., 1997, Virtual Politics. Identity and Community in Cyberspace, Londres, Sage, $248 \mathrm{p}$.

LEDUN M., 2005, La démocratie assistée par ordinateur. Du sujet politique au consommateur à caractère politique, Paris, Connaissance et Savoirs, 568 p.

LÉVY P., 1997, Cyberculture, Paris, Odile Jacob, 313 p.

LOISEAU G., 1999, Municipalités et communication numérique. Les sites Internet des grandes villes de France en 1999, Paris, Université Paris 1, http://www.multimediaville. tm.fr/pages/multi200o/Synthese.html.

- 2000, «La démocratie électronique municipale française: au-delà des parangons de vertus », Hermès, n 26-27, p. 213-232.

MANN M., 1995, Politics on the Net, Indianapolis, Que Corporation, 382 p.

MARCOCCIA M., 2003, "Parler politique dans un forum de discussion », Langage et société, $\mathrm{n}^{\circ}$ 104, p. 9-55.

MARGOLIS M. et RESNICK D., 2000, Politics as Usual: the Cyberspace Revolution, Londres, Sage, $246 \mathrm{p}$.

MOURLHON-DALLIES F., RAKOTONOELINA F. etREBOUL-TOURÉ S. éd., 2004, « Les discours de l'Internet: nouveaux corpus, nouveaux modèles? ", Les Carnets du Cediscor, n 8 , $193 \mathrm{p}$.

NEGROPONTE N., 1995, L'Homme numérique, Paris, Laffont, 295 p.

OTMAN G., 1998, Les mots de la cyberculture, Paris, Belin, 474 p.

PAILLIART I., 2000, « Les enjeux locaux de la démocratie électronique », Hermès, nº 26 27, p. 129-140.

PAL L. A. et ALEXANDER C. J., 1998, Digital Democracy: Policy and Politics in the Wired World, Don Mills, Oxford University Press, $237 \mathrm{p}$.

PELISSIER N. et EVANGHELOU A., 2000, «Orwell à Athènes: la cyberdémocratie au chevet de la démocratie », Quaderni, n 41, p. 109-139. 
POSTER M., 1997, «Cyberdemocracy: Internet and the public sphere », D. Porter éd., Internet Culture, Londres, New York, Routledge, p. 201-218.

PROULX S. et VITALIS A. éd., 1999, Vers une citoyenneté simulée: médias, réseaux et mondialisation, Rennes, Apogée, 267 p.

RASH W. R., 1997, Politics on the Nets, New York, W. H. Freeman and Company, 206 p.

RODOTA S., 1999, La démocratie électronique, Rennes, Apogée, 186 p.

SERFATY V. éd., 2003, L'Internet en politique, des États-Unis à l'Europe, Strasbourg, Presses universitaires de Strasbourg, $424 \mathrm{p}$.

SFEZ L., 1992, Critique de la communication, Paris, Le Seuil, 520 p.

SOUCHIER E., JEANNERET Y. et LE MAREC J. éd., 2003, Lire, écrire, réécrire. Objets, signes et pratiques des médias informatisés, BPI, Centre Pompidou (Étude et recherche), $348 \mathrm{p}$.

SOUCHIER E. éd., 2004, "Le signe en scène, un enjeu politique », Communication et langages, $\mathrm{n}^{\circ} 142,114 \mathrm{p}$.

STRAUSS F., 2004, « Kampagne: Politik als Marke. Frau Kurasten sucht Orientierung », Politik und Kommunikation, $\mathrm{n}^{\circ}$ 15, p. 24-26.

WILHELM A., 2000, Democracy in the Digital Age. Challenge to Political Life in Cyberspace, Londres, Routledge, $184 \mathrm{p}$.

WOLTON D., 1999, Internet et après? Une théorie critique des nouveaux médias, Paris, Flammarion, $240 \mathrm{p}$.

YILDIZ H., 2003, « Internet: un nouvel outil de communication multidimensionnelle », V. Serfaty éd., L'Internet en politique, des États-Unis à l'Europe, Strasbourg, Presses universitaires de Strasbourg, p. 275-290.

Marc Bonhomme, Michael Rinn 